\title{
FACT: An Air-Ground Communication Framework for Seeding Quality Control of Aircraft
}

\author{
Dequan $\mathrm{Li}^{1,2}$, Jiming $\mathrm{Li}^{1,2}$, Xu Zhou ${ }^{1,2}$, JinRong $\mathrm{Hu}^{3}$, Xin Wang ${ }^{4}$ and Jing Duan ${ }^{1,2, *}$ \\ ${ }^{1}$ State Key Laboratory of Severe Weather, Chinese Academy of Meteorological Sciences, Beijing, 100081, China \\ ${ }^{2}$ Key Laboratory for Cloud Physics of China Meteorological Administration, Beijing, 100081, China \\ ${ }^{3}$ Chengdu University of Information Technology, Chengdu, 610225, China \\ ${ }^{4}$ Curacloud Corporation, Seattle, WA, 98104, USA \\ *Corresponding Author: Jing Duan. Email: duanjing@cma.gov.cn \\ Received: 16 April 2021; Accepted: 27 June 2021
}

\begin{abstract}
A new type of air-ground communication application framework named FACT (framework for air-ground communication technology with weather-modification aircraft) is presented to track and command weather-modification aircraft to perform ideal cloud seeding. FACT provides a set of solutions from three perspectives, namely, onboard, onground and air-to-ground, with the core purpose of solving the problems of the rapid exchange of information, contract analysis and identifying potential seeding areas when flight plans and meteorological conditions change. On board, the observed data are processed centrally and transmitted downward through air-to-ground communication. The real-time application and sharing of aircraft detection data are strengthened on the ground, and potential areas of operation are automatically identified based on ground data. The communication between the air and the ground achieves a technical breakthrough by realizing double satellite links, adaptive data transmission and VPN channel encryption. Additionally, an application based on FACT is designed and implemented for the real-time command of weather-modified aircraft. This approach has become the key air-to-ground communication system support for more than 40 Chinese aircraft and the big data service support center of airborne data to ensure improved operation of weather-modification aircraft in China.
\end{abstract}

Keywords: Air-ground communication; application framework; aircraft operation; data transmission and analysis

\section{Introduction}

Weather modification is to reduce or avoid meteorological disasters by consciously influence on the local atmospheric physical and chemical processes through scientific and technological means. The cloud seeding is the most common form of weather modification. The multiple advanced seeding tools are applicated in weather modification activities, such as aircraft, ground-based rockets, artillery and generators [1]. Weather modification via aircraft cloud seeding is often regarded as an important means to enhance

This work is licensed under a Creative Commons Attribution 4.0 International License, which permits unrestricted use, distribution, and reproduction in any medium, provided the original work is properly cited. 
rainfall and plays an important role in drought resistance, forest fire prevention and extinguishment, increasing reservoir water storage, and improving and protecting the ecological environment [2-6].

As high-speed aircraft quipped with precise detection instruments and seeding devices, weathermodified aircraft have flight processes that include two phases: aviation flight (including meteorological detection) and seeding operations. Therefore, such aircraft are not only restricted by aviation safety management but also must comply with operational specifications for weather modification operations. These aircraft are both under the joint command of the air traffic control department and the ground weather modification command center.

Weather-modification aircraft operations refer to cloud seeding by aircraft in this work; that is, the aircraft flies along the preapproved route to a designated location, where the catalyst is spread into the clouds, which has achieved the purpose of enhancing rainfall. An ideal seeding effect means that the catalyst is successfully spread in a cloud with high potential, which effectively promotes the formation of new raindrops in the cloud, thereby allowing more cloud water to fall on the ground to form rainfall and ultimately increase precipitation. To gain a good effect, it is necessary to establish a wireless communication system between the air and ground [7-10], which is connected to each other to determine the next action, discuss and determine the flight plan or the change in the seeding time and location.

Air-to-ground communication usually includes two parts. One part refers to the communication between the aircraft pilot and the ground tower, and the other part refers to the communication between the aircraft and the ground command center. We focus on the latter in this paper. These air-ground communication systems mainly transmit information by communication satellites in the form of telephone calls and short messages. This communication method is based on manual interaction, and the information exchange is irregular and discontinuous and limited in quantity. For a long time, there has been little communication or only flight trajectory data exchange and a small number of messages between the air and ground during a flight. Observation data from a plane were not communicated with the ground, and remote-sensing observations on the ground were not uploaded to the plane. Therefore, aircraft often follow the original flight plan for seeding without any modifications. If the aircraft finds that the original plan does not match the actual conditions (for example, there are no clouds in the operation area), the decision-making power belongs to the aircraft. The individuals on the aircraft can analyze the conditions, find an appropriate seeding area and decide whether to change the route. After takeoff, the only task for the ground command center is to monitor the flight safety of the aircraft and confirm whether the aircraft route and cloud seeding are proceeding as planned. Clearly, cloud condition judgment based on a single type of observed data has limitations, and it is best to mutually verify with other types of observed data. When looking for a new seeding time and place, the lack of comprehensive information, either airborne observation or groundbased remote sensing detection, will make it difficult to provide a comprehensive and scientific judgment.

As shown in Fig. 1, the dashed frame is the new subprocess after introducing airborne observation data to the ground command center via an air-ground communication system. Compared with the original process, the amount of cloud information and decision-making role on the ground have been greatly enhanced.

How to make good use of aircraft observations during aircraft flight is one of the key issues to improve the quality of seeding operations. In response to this problem, a new framework with high air-to-ground communication information support and decision-making capabilities is proposed, which realizes the realtime transmission of airborne observations from aircraft to the weather modification ground command center, and a new method to ensure uninterrupted transmission and automatically identify the seeding potential area. In this framework, relying on air-ground-based observations, automated data reanalysis is performed to help experts determine the potential seeding area around the aircraft flight path, thereby temporarily adjusting some of the routes and ultimately achieving the goal of improving seeding effectiveness. 


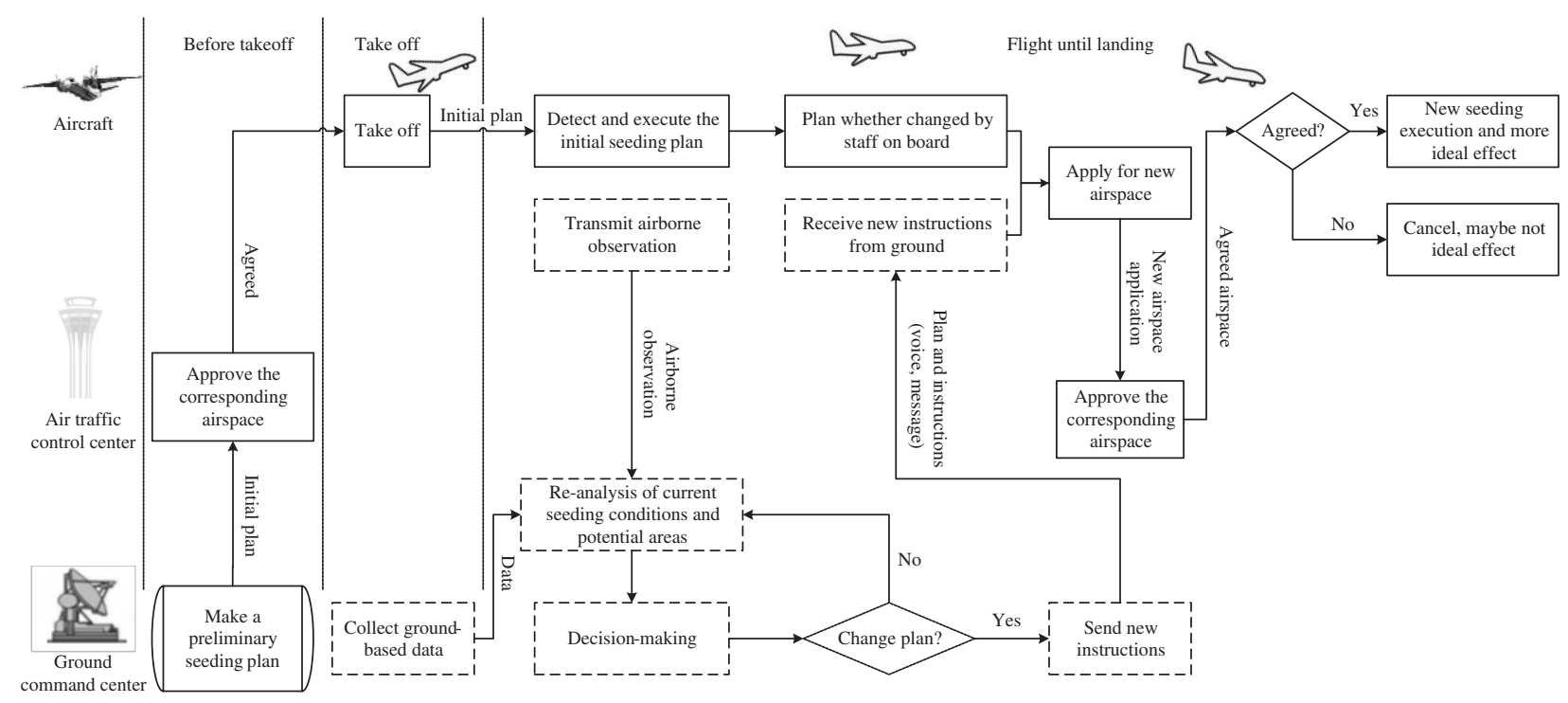

Figure 1: Workflow of weather-modification aircraft after introducing air-ground communication

\section{Related Works}

The scientific basis for cloud seeding originates from the cloud microphysical phenomena discovered by Schaefer and Vonnegut [11,12]. All kinds of observed parameters from cloud microphysical phenomena are important aspects to describe cloud characteristics. To pass through the cloud directly, aircraft detection has become one of the most effective means to obtain cloud microphysical parameters. Equipped with particle measuring systems (PMSs), aircraft automatically sample, measure and record cloud particles and continuously observe a wide range of clouds.

In recent years, two companies, DMT (droplet measurement technologies) and SPEC (Stratton Park Engineering Company), have developed a series of instrument probes to measure cloud particles, such as CDP (cloud droplet probe), CIP (cloud imaging probe), and PIP (precision imaging probe), which refine cloud microphysical parameters and understand cloud dynamic and microphysical processes. Aircraft observations and cloud seeding are widely used in weather modification research and experiments. For example, the SNOWIE project is used to understand organic cloud dynamic and microphysical processes and addresses long-standing uncertainties regarding the effectiveness of organic cloud seeding $[13,14]$. Furthermore, the microphysical characteristics of clouds observed by aircraft play an important role in climate research and the determination of cloud parameterization schemes in numerical models [15-17]. In addition, remote sensing data, such as radar and satellites, are more helpful to evaluate the precipitation enhancement effectiveness through the value change of cloud parameters between pre- and post-cloud seeding.

An aircraft seeding operation that successfully spreads the catalyst and achieves good seeding results requires three problems to be solved: timing, location, and dosage. Timing refers to the time period for the execution of aircraft operations based on various meteorological observation data and forecast analysis. Location refers to the area where the aircraft needs to spread the catalyst, and these areas must be on the flight path of the aircraft. Dosage refers to the type and dosage of catalyst to ensure that the microphysical process in the cloud is performed in the expected direction to achieve the expected purpose, such as the formation of precipitation. 
An improvement in the accuracy and precision of these three factors will improve the weather modification effectiveness of the aircraft. When the aircraft takes off, the approximate range of time it can seed (i.e., the maximum flight time) and the amount of catalyst carried by the aircraft are determined. Therefore, according to the observed cloud microphysical data, the ability of air-to-ground communication to improve the seeding effectiveness depends on the ability to locate new seeding potential and the scientific decision of seeding positions on the flight path.

At present, China's weather modification aircraft are equipped with Beidou satellite communication equipment $[18,19]$. All communications are based on short messages. The ground center can only acquire flight status without aircraft observation once a minute on average. However, there are no ground data available on the plane, so the staff on board have to read the airborne observation manually, judge the potential area according to their own experience, and decide whether to continue the initial plan.

Machine learning methods are helpful to improve the ability of multisource data processing and provide real-time decision suggestions. Many works over the past years have been proposed on flexible machine learning techniques for meteorological data processing. For instance, generative adversarial networks (GANs) can generate a reasonable two-dimensional vertical cloud structure and infer the complex multilayer cloud structure observed by MODIS [20]. Deep learning, neural networks, and convolutional neural networks (CNNs) have been used for the classification and prediction of clouds, wind and precipitation [21-24]. Within a radar processing context, approaches for radar quantitative precision estimation (QPE) and computer vision have been proposed [25-27]. Aguilar et al. [28] shows the

decision tree as an analytical method that is suitable for making decisions in the automation of natural ventilation in a nonindustrial closed environment.

\section{Proposed Approach}

A key to improving the seeding quality is to transmit airborne observations down to the ground, combined with ground observations to quickly find potential areas, which is important decision-making support for whether to change the flight route. The difficulty lies in the integration of transmission, automatic identification and decision-making. Consequently, there are three ways to solve this problem: onboard, between the air and ground, and on the ground.

\subsection{Framework for Air-Ground Communication in Weather-Modification Aircraft Operations}

In view of the above requirements, a framework named FACT (framework for air-ground communication technology with weather-modification aircraft) is developed to present a novel approach for using air-ground communication and decision-making support to improve the seeding effectiveness of weather modification aircraft. The internal structure of the two components of FACT, a typical hierarchical structure, is shown in Fig. 2.

FACT divides air-ground communication and commands into two components, onboard and onground, which are also called the air and ground poles, and solves the communication and command needs of onboard and onground commanders in terms of communication, data, and application. The two poles are connected, and satellite links are established to realize information reception and feedback between the air and ground. On-ground components are deployed at many national or provincial ground command centers and airports to track and direct aircraft operations. On-board components are loaded in the cabin of the operating aircraft and perform specific tasks, such as cloud microphysics observation, dissemination of catalyst, collection of the aircraft's own status, and information exchange. 
On-board part

User
Terminal
on board
$\begin{gathered}\text { Flight status } \\ \text { monitoring }\end{gathered}$

Meteorological Broadband
Network on ground

Figure 2: System structure of FACT 
Compared to the on-board components, the on-ground components have a large network bandwidth and more powerful data processing, storage, and service capabilities. In addition to the data transmitted by the aircraft in real time, other meteorological data can be obtained by the ground network to complete the fusion analysis from multiple data sources. Furthermore, each ground command node is equipped with a team of experts to propose suggestions and assist in comprehensive decision making. Thus, the ground node has gradually become the core of air-ground communication.

\subsection{Solutions on the Aircraft}

The onboard part of FACT is divided into five separate layers in Fig. 2, with each layer handling a different aspect of the communication problem in weather modification operations.

1) The on-board terminal provides a human-machine interaction UI on the workstation for the weather modification operators on the aircraft, making it convenient and fast to display on-board observation data, operate seeding equipment, and receive ground instructions and feedback in real time. All the information provided by the terminal comes from the data storage layer.

2) Data storage is used to store four types of data on the aircraft. The first kind of data is various types of aircraft observation data acquired from on-board detection instruments and stored in the aircraft observation database. The second type of data is obtained from the seeding job control equipment and is stored in the seeding information database. The third type of data includes various types of interactive information and files uploaded from the ground via satellite transmission and is stored in the air-ground information exchange database. The fourth type of data is the running status data collected from equipment on the aircraft, which is stored in the device operating status database.

3) Data collection involves collecting various types of cloud microphysical observation data from various detection instruments on the aircraft, obtaining real-time operation information from the seeding control equipment, and obtaining running status from each piece of equipment. The collected data goes directly to storage.

4) Air-to-ground transmission uses Beidou/Inmarsat satellite communication equipment to establish a stable satellite link between the aircraft and the ground for specific data transmission purposes. Furthermore, the communication channel and data are encrypted according to the user requirements. Short message transmission via Beidou and streaming information transmission via the Inmarsat satellite are also supported. After the data uploaded by the ground are received, they are directly submitted to the data storage layer for service.

5) Device resources provide many necessary resources, such as satellite communication, onboard internal networks, observation and operation equipment, and workstations, headsets, microphones and other hardware resources necessary for normal operation of the on-board system.

\subsection{Communication Solutions Between the Air and Ground}

In FACT, the subsystem between the air and ground focuses on solving the real-time data transmission and improving the exchange efficiency and command interaction convenience between the air and ground.

\subsubsection{Data Exchanged Between the Air and Ground}

In FACT, the data are exchanged by satellite between the air and ground (see Tab. 1).

The data that are transmitted continuously include flight status, basic meteorological elements, cloud microphysical observation data, seeding information, and device status. The voice, operation plan and instructions are transmitted irregularly according to the actual conditions. 
Table 1: Data exchanged by satellite

\begin{tabular}{|c|c|c|c|c|}
\hline Data & Type & Content & Frequency & $\begin{array}{l}\text { Satellite } \\
\text { channel }\end{array}$ \\
\hline $\begin{array}{l}\text { Cloud } \\
\text { microphysical } \\
\text { data }\end{array}$ & Bit stream & $\begin{array}{l}\text { High-precision photos of clouds, icing } \\
\text { images, and spectra of cloud droplet } \\
\text { particles (such as the instruments: CDP, } \\
\text { CIP, PIP, etc.) They are important basis } \\
\text { for meteorologists to judge cloud types, } \\
\text { liquid water content, and seeding } \\
\text { conditions. }\end{array}$ & Regular, e.g., 1/sec. & Inmarsat \\
\hline Flight status & Text & $\begin{array}{l}\text { Aircraft number, date, time, longitude, } \\
\text { latitude, altitude, speed, heading, and } \\
\text { other flight parameters. They are essential } \\
\text { for the ground command center to track } \\
\text { and understand the dynamics of each } \\
\text { aircraft. }\end{array}$ & $\begin{array}{l}\text { Regular, e.g., } 1 / \mathrm{sec} \\
\text { for Inmarsat, } 1 / \mathrm{min} \text {. } \\
\text { for Beidou. }\end{array}$ & $\begin{array}{l}\text { Inmarsat/ } \\
\text { Beidou }\end{array}$ \\
\hline $\begin{array}{l}\text { Seeding } \\
\text { information }\end{array}$ & Text & $\begin{array}{l}\text { Type and amount of catalyst, the location } \\
\text { and time of starting and stopping for each } \\
\text { catalyst seeding. It is an important basis } \\
\text { for subsequent calculation of the seeding } \\
\text { area and evaluation of the modification } \\
\text { effectiveness. }\end{array}$ & $\begin{array}{l}\text { Irregular, only } \\
\text { transmit when } \\
\text { seeding. }\end{array}$ & $\begin{array}{l}\text { Inmarsat/ } \\
\text { Beidou }\end{array}$ \\
\hline $\begin{array}{l}\text { Basic } \\
\text { meteorological } \\
\text { elements }\end{array}$ & Float & $\begin{array}{l}\text { Basic observations such as pressure, } \\
\text { temperature, and humidity. }\end{array}$ & Regular, e.g., 1/sec. & $\begin{array}{l}\text { Inmarsat/ } \\
\text { Beidou }\end{array}$ \\
\hline Operation plan & $\begin{array}{l}\text { Document } \\
\text { format }\end{array}$ & $\begin{array}{l}\text { The scheduled flight route, and the area } \\
\text { and time of seeding. }\end{array}$ & $\begin{array}{l}\text { Irregular, only } \\
\text { Transmit when } \\
\text { needed. }\end{array}$ & Inmarsat \\
\hline Instruction & Text & $\begin{array}{l}\text { The command exchanged between the air } \\
\text { and the ground through short messages. }\end{array}$ & $\begin{array}{l}\text { Irregular, only } \\
\text { Transmit when } \\
\text { needed. }\end{array}$ & $\begin{array}{l}\text { Inmarsat/ } \\
\text { Beidou }\end{array}$ \\
\hline $\begin{array}{l}\text { Voice } \\
\text { commands }\end{array}$ & Bit stream & $\begin{array}{l}\text { The information exchanged between the } \\
\text { air and the ground through voice. }\end{array}$ & $\begin{array}{l}\text { Irregular, only } \\
\text { Transmit when } \\
\text { needed. }\end{array}$ & Inmarsat \\
\hline Device status & Bit stream & $\begin{array}{l}\text { Working status, current, and voltage of } \\
\text { each device. }\end{array}$ & Regular, e.g., 1/min. & Inmarsat \\
\hline
\end{tabular}

\subsubsection{Dual Satellite Link for Mutual Backup Transmission}

A dual satellite link for mutual backup transmission balances timeliness, stability and economic factors. The satellite channel for each data point is shown in Tab. 1.

Relying on the different advantages of the Inmarsat and Beidou satellites, FACT has established a nationwide dual-link satellite transmission network for weather modification services. Compared to the 
widely used air-ground communication and command applications that rely solely on a single satellite link, the dual link greatly improves the functionality, performance and stability.

Compared to the previous single-link method to command aircraft via short messages [23-26], FACT supports a variety of new interactive command methods, such as short messages, audio calls, new seeding plan notifications, and scheduled image delivery. Furthermore, the shortest interval for short message communication is reduced from minutes to seconds.

FACT makes full use of the characteristics of Beidou satellites, i.e., wide coverage, short message-based communication, regular fixed-location transmission, and low cost. These satellites are used as the mainstream transmission method to acquire flight status, seeding operation information, and instructions and as an alternative transmission method for aircraft.

On the other hand, although the Inmarsat satellite has high transmission costs, it also has technical advantages, such as stable signals during high-speed flight, stream-based transmission, and short transmission intervals. Therefore, Inmarsat satellites, as the main transmission means for highperformance operational aircraft, focus on transmitting seeding information, documents, files, audio streams and airborne observation data with high spatial and temporal resolution. This design takes into account aircraft characteristics, satellite transmission technology differences, and transmission costs and has proven to be economically feasible in practice.

For data transmission via Inmarsat satellites, FACT sets up a virtual private network (VPN) to support transmission encryption. VPN tunnels exist between each node (aircraft, ground command center), and tunnel encryption technology is implemented. Digital certificates and user names/passwords are used for identity verification. Moreover, message and voice data are encrypted in the VPN to prevent data from being intercepted and tampered with and to improve the information security and reliability of the entire system operation.

\subsubsection{Adaptive Data Extraction for Airborne Observation to Transmit}

In the case of sudden centralized service tasks, such as performing rain enhancement operations around the same fire point, when a large number of aircraft are concentrated in intensive seeding operations in one or several areas within a short time, Inmarsat satellite communication beams in this area may compete with each other. This problem further reduces the satellite transmission quality, bandwidth, and transmission efficiency of each aircraft and will cause congestion in downloading aircraft data and interfere with the data display and command, even when the ground command center does not update the display for a long time. In response to this situation, FACT adopts intelligent and dynamic adjustment of transmission strategies when the bandwidth and quality of the Inmarsat link are reduced. This strategy effectively reduces network congestion without significantly affecting the quality of the data displayed on the ground command center.

Due to the instability of the current Inmarsat satellite channel, the principle of linear proportion extraction based on the transmission quality of the data link is used to extract the original data and send data. The original airborne observation data generate one record per second. When the original data are transmitted downward through the satellite, the time interval may be greater than or equal to one second; that is, it may take several seconds for one record to be transmitted downward. This time interval is calculated dynamically according to the transmission quality of the satellite channel, and the time interval is adjusted every other time period $T_{p}$ (a time window is defined, e.g., $2 \mathrm{~min}$ ). The whole process is a dynamic calculation process that is performed according to Eq. (1), as follows:

$T_{n+1}=\operatorname{argmax}\left(T_{n} * \operatorname{argmin}\left(1+\frac{L\left(T_{n-1}\right)-L\left(T_{n}\right)}{\left|L\left(T_{n-1}\right)-L\left(T_{n}\right)\right|} * \frac{L\left(T_{n-1}\right)}{L\left(T_{n}\right)}, 1\right), T_{n-1}\right), n \geq 1$ 
where the argmax function represents the larger of the two numbers. The argmin function takes the smaller of the two numbers. $T_{0}=T_{1}=10$ indicates that the initial average extraction interval is $10 \mathrm{~s} . T_{n+1}$ is the average extraction interval when sending data to the ground center in the $(n+1)^{\text {th }}$ time period $T_{p}$ (i.e., $2 \mathrm{~min}$ ), and $L$ is the satellite link quality evaluation function, as shown in Eq. (2). The satellite link quality is dynamically measured according to the parity check error rate during data transmission in the last period. The quality takes a value of $0-100$ : the higher the value is, the better the satellite link quality.

$L(x)=\left(1-\frac{\sum_{t=x}^{x+T_{p}} E(t)}{\sum_{t=x}^{x+T_{p}} N(t)}\right) * 100$

where $E(t)$ is the number of bits with parity check errors in $t^{t h}$ seconds. $N(t)$ is the total number of bits transmitted in $t^{\text {th }}$ seconds.

\subsection{Solutions on the Ground}

In FACT, the ground system focuses on decision-making support and data sharing among various ground command centers.

\subsubsection{Composition of the Ground Component of FACT}

The on-ground component of FACT is divided into six separate layers, with each layer handling different aspects of communication or data sharing.

1) Device resources. This layer provides satellite communication, terrestrial broadband networks, data servers and workstations, headsets, microphones and other hardware resources necessary for the normal communication of the ground system.

2) Air-to-ground transmission. The ground establishes a satellite link with the on-board satellite communication equipment. The communication channel and data are encrypted according to the user's requirements. Data received from the aircraft are directly stored in the relevant database in the ground data storage layer.

3) Data collection. This layer is responsible for collecting various observation data on the ground, such as radar, raindrop spectrum, lightning, rainfall and other observations. These data are combined with observation data transmitted from the aircraft, resulting in a more accurate analysis of cloud conditions in the flight area.

4) Data storage. This layer is similar to the on-board storage design. The data obtained from the aircraft are also stored in the database on the ground in airborne observation databases, seeding information databases, air-ground command communication databases, and device operating status databases. In addition, remote sensing data collected from the ground, such as radar, raindrop spectrum, lightning, rainfall and other data used for air-ground data fusion analysis, are also stored.

5) Unified service. This layer, which is unique to the ground, provides unified access services considering the need for air-ground data sharing between ground command centers at all levels. Services are provided in the form of interfaces, including data interfaces that focus on data reading and storage and command interfaces that send instructions directly to aircraft.

6) The ground terminal. Different from the on-board terminal, the ground terminal is aimed at more users, including ground commanders, experts on the ground to assist in analysis and decision making, and management personnel. The ground terminal also provides functions similar to those provided by the on-board terminal, such as real-time monitoring of aircraft flight and seeding operations, air-ground transmission status, real-time display of on-board observation data at the same time with the aircraft, and interactive commands such as short messages and voice transmissions between the air and ground. In 
addition, the ground terminal provides new functions, such as flight status warnings and reminders, fusion displays and analysis of air-ground data, to quickly discover potential areas based on new cloud conditions. These new functions take advantage of on-ground capabilities related to data collection and calculation and combine aircraft and ground data to facilitate the rapid analysis and decision making of ground commanders and expert groups.

\subsubsection{Simultaneous Data Display and Decision-Making}

Previously, aircraft observations were only viewed in real time on board, not on the ground. With FACT, these data are not only transmitted to the ground command center in real time but also displayed synchronously on workstations to improve the rapid response capability. The display time on the ground is only one second delayed compared to the aircraft. Furthermore, a decision tree algorithm as a methodology for automatic cloud potential identification is also proposed in FACT. These are advantages of FACT over previous weather-modification command systems.

Many factors must be considered when searching for the best seeding position. For example, there must be an object that can be seeded (i.e., a cloud), and the cloud must have potential; that is, the cloud should form precipitation after spreading the catalyst. A cold cloud catalyst or warm cloud catalyst can be selected according to the type of cloud. For cold clouds, when ice crystals and supercooled water exist and are abundant, seeding in a temperature range of -5 to $-25^{\circ} \mathrm{C}$ can result in better precipitation enhancement. In addition, clouds are constantly moving, so the flight route must be adjusted in real time. The basis of using air-to-ground communication to improve the seeding effect is to consider various kinds of data collected in real time to identify potential operation objects and locations within the flight area that the aircraft can reach and then perform the appropriate seeding operation.

According to the number of available airborne observation instruments and expert experience in the field of weather modification, we select the relevant variables in Tab. 2. The typical scenario to analyze a cloud with high potential by those variables and their values is shown in Tab. 3. The final column, which displays a YES or NO in Tab. 3, is the expert conclusion of whether it is a cloud seeding potential area based on the actual flight sorties.

The decision tree is employed to predict cloud seeding potential by classification. A scenario with many possible real air-based and ground-based environmental conditions around aircraft is built that includes the variables and a decision column. Fig. 3 shows the decision tree, which is built by the C4.5 algorithm, obtained from the scenario with many possible real air-based and ground-based environmental conditions around the aircraft of Tab. 3. Based on this decision tree, once real-time values related to the variables acquired in the ground command center, it automatically predicts whether there is potential for the path of the aircraft.

\subsubsection{Interface for Data Service and Command Interaction}

During the operation of weather-modified aircraft, there are often multiple command centers on the ground to monitor and command the aircraft simultaneously. These centers need to share real-time aircraft trajectory and airborne observation data. Based on air-ground communication and ground meteorological broadband networks, FACT establishes integrated data storage and unified services and constructs the key underlying data support of the entire set of ground command centers and aircraft groups.

FACT provides two types of interfaces: a data interface and a command interface. Both interfaces are designed with an application programming interface (API) in the form of representational state transfer (REST). The data interface allows users to obtain data directly from the database within the ground command center, and the results, such as the device status, airborne observation data files, and operating status (airplane flight trajectory and seeding status), are returned to the front-end application. The 
command interface is mainly used by users at the ground command center to directly send command text messages and plan files to an aircraft to immediately command this aircraft.

Table 2: Variable values for cloud

\begin{tabular}{|c|c|c|}
\hline Variable & Values & Interpretation \\
\hline Cloud type (CT) & $\begin{array}{l}\text { COLD/WARM/ } \\
\text { CLOUDLESS }\end{array}$ & $\begin{array}{l}\text { COLD: Temperature between }-25 \text { and } \\
-5^{\circ} \mathrm{C} \\
\text { WARM: Temperature higher than } 0^{\circ} \mathrm{C} \\
\text { CLOUDLESS: No Cloud }\end{array}$ \\
\hline Cloud observed (CO) & IN/OUT & $\begin{array}{l}\text { IN: aircraft in the cloud or CDP }>10 \\
\text { OUT: aircraft out of the cloud or CDP }<0.5\end{array}$ \\
\hline Vertical wind speed (VWS) & $\begin{array}{l}\text { LOWER/LOW/ } \\
\text { NORMAL/HIGH }\end{array}$ & $\begin{array}{l}\text { LOWER: wind speed less than } 0.05 \mathrm{~m} / \mathrm{s} \\
\text { LOW: speed between } 0.05 \text { and } 0.2 \mathrm{~m} / \mathrm{s} \\
\text { NORMAL: speed between } 0.2 \text { and } 0.5 \mathrm{~m} / \mathrm{s} \\
\text { HIGH: speed higher than } 0.5 \mathrm{~m} / \mathrm{s}\end{array}$ \\
\hline Liquid water content (LWC) & $\begin{array}{l}\text { LOWER/LOW/ } \\
\text { NORMAL/HIGH }\end{array}$ & $\begin{array}{l}\text { LOWER: LWC less than } 0.0001 \mathrm{~g} / \mathrm{m}^{3} \\
\text { LOW: LWC between } 0.0001 \text { and } \\
0.001 \mathrm{~g} / \mathrm{m}^{3} \\
\text { NORMAL: LWC between } 0.001 \text { and } \\
0.01 \mathrm{~g} / \mathrm{m}^{3} \\
\text { HIGH: LWC higher than } 0.01 \mathrm{~g} / \mathrm{m}^{3}\end{array}$ \\
\hline $\begin{array}{l}\text { Cloud droplet number } \\
\text { concentration (CDNC) }\end{array}$ & $\begin{array}{l}\text { LOWER/LOW/ } \\
\text { NORMAL/HIGH }\end{array}$ & $\begin{array}{l}\text { LOWER: value less than } 0.1 \\
\text { For droplet number concentration value } \\
\text { observed by CDP. } \\
\text { LOW: value between } 0.1 \text { and } 0.5 \\
\text { NORMAL: value between } 0.5 \text { and } 1 \\
\text { HIGH: value higher than } 1\end{array}$ \\
\hline Ice/snow crystal image (ISCI) & YES/NO & $\begin{array}{l}\text { YES: CIP image appears and lasts more } \\
\text { than } 5 \mathrm{~s} \\
\text { NO: no image or image duration }<5 \mathrm{~s}\end{array}$ \\
\hline Radar reflectivity (dBZ) & $\begin{array}{l}\text { LOW/NORMAL/ } \\
\text { HIGH }\end{array}$ & $\begin{array}{l}\text { LOW: value less than } 15 \\
\text { NORMAL: value between } 15 \text { and } 25 \\
\text { HIGH: value higher than } 25\end{array}$ \\
\hline $\begin{array}{l}\text { Optical Thickness for FY- } \\
2 \text { satellite (OPTN) }\end{array}$ & $\begin{array}{l}\text { LOW/NORMAL/ } \\
\text { HIGH }\end{array}$ & $\begin{array}{l}\text { LOW: value less than } 15 \\
\text { NORMAL: value between } 15 \text { and } 40 \\
\text { HIGH: value higher than } 40\end{array}$ \\
\hline $\begin{array}{l}\text { Effective particle radius for FY- } \\
2 \text { satellite (EPR) }\end{array}$ & $\begin{array}{l}\text { LOW/NORMAL/ } \\
\text { HIGH }\end{array}$ & $\begin{array}{l}\text { LOW: value less than } 10 \mu \mathrm{m} \\
\text { NORMAL: value between } 10 \text { and } 20 \mu \mathrm{m} \\
\text { HIGH: value higher than } 20 \mu \mathrm{m}\end{array}$ \\
\hline
\end{tabular}


Table 3: Scenario for automated identification of cloud seeding potential

\begin{tabular}{lllllllllll}
\hline Number & CT & CO & VWS & LWC & CDNC & ISCI & dBZ & OPTN & EPR & Decision \\
\hline 1 & COLD & IN & LOW & NORMAL & NORMAL & YES & HIGH & NORMAL & NORMAL & YES \\
2 & COLD & IN & LOW & HIGH & HIGH & YES & HIGH & HIGH & LOW & YES \\
3 & COLDLESS & OUT & LOWER & LOWER & LOWER & NO & LOW & LOW & LOW & NO \\
4 & COLDLESS & OUT & LOW & LOW & LOWER & NO & LOW & LOW & LOW & NO \\
5 & COLD & IN & HIGH & HIGH & HIGH & YES & HIGH & HIGH & HIGH & YES \\
6 & COLD & IN & LOW & NORMAL & NORMAL & NO & NORMAL & HIGH & NORMAL & NO \\
7 & COLD & IN & HIGH & HIGH & HIGH & YES & HIGH & HIGH & HIGH & YES \\
8 & COLD & IN & LOW & HIGH & HIGH & NO & NORMAL & HIGH & HIGH & YES \\
9 & COLD & IN & LOW & NORMAL & NORMAL & YES & HIGH & NORMAL LOW & NO \\
10 & COLD & IN & NORMAL & HIGH & NORMAL & YES & HIGH & HIGH & HIGH & YES \\
11 & COLDLESS & OUT & LOW & LOWER & LOW & NO & LOW & NORMAL LOW & NO \\
12 & COLDLESS & OUT & LOW & LOWER & LOWER & NO & NORMAL & LOW & LOW & NO \\
13 & COLD & IN & NORMAL & NORMAL & NORMAL & NO & NORMAL & NORMAL NORMAL & YES \\
14 & COLD & OUT & LOW & LOWER & LOWER & NO & LOW & NORMAL LOW & NO \\
\hline
\end{tabular}

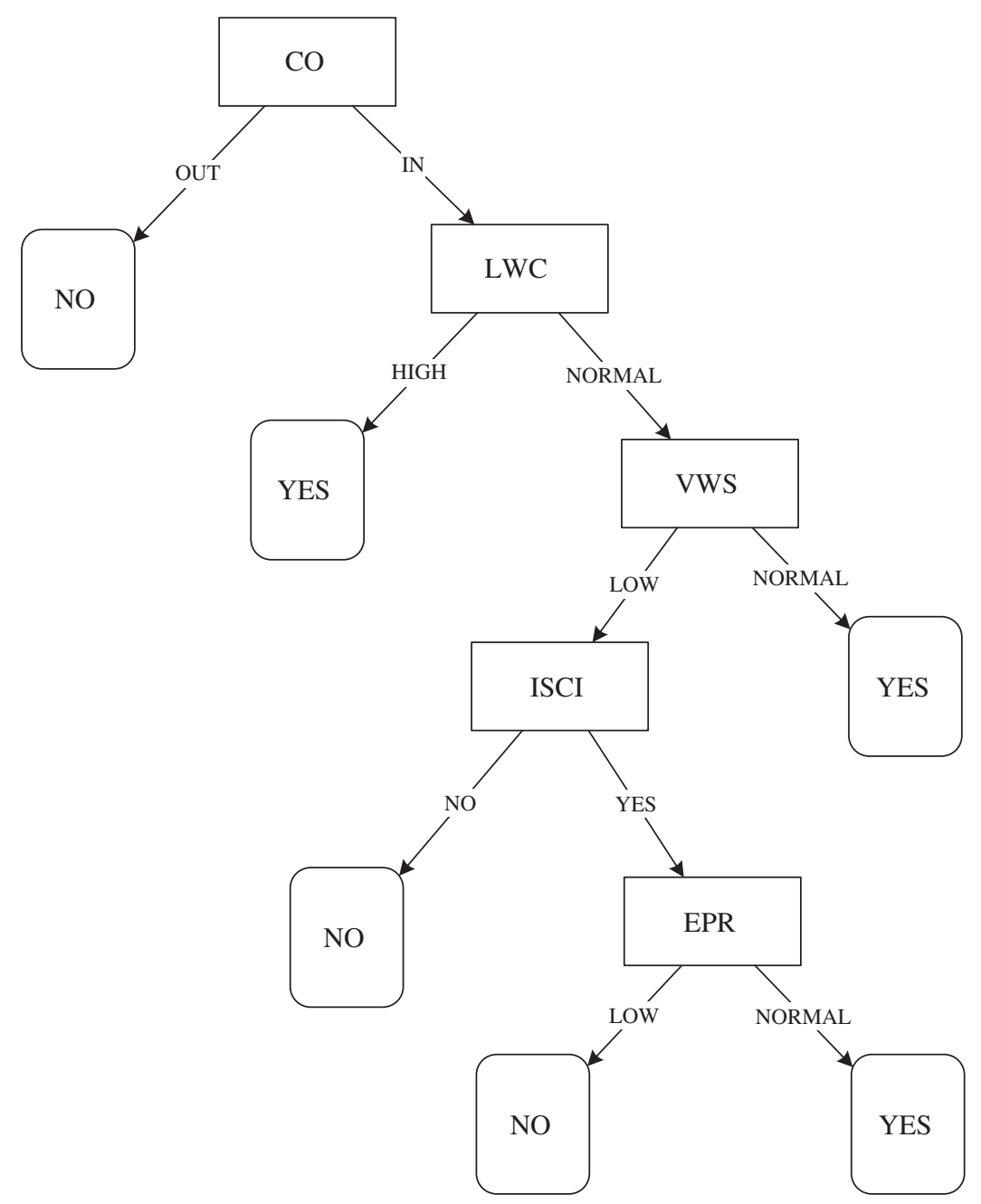

Figure 3: Decision tree for classification of seeding potential 


\section{Experiment and Applications}

\subsection{Application Coverage}

Based on FACT, the Weather Modification Center of the China Meteorological Administration has designed and implemented a real-time air-ground communication command application for weathermodification aircraft operations, which is called NACS, the National Air-ground Communication System. NACS provides a new set of tools, including satellite communication transmission, data storage and service, and client applications, to ensure flight safety and improve target selection for aircraft seeding. Fig. 4 shows the functional structure of NACS.

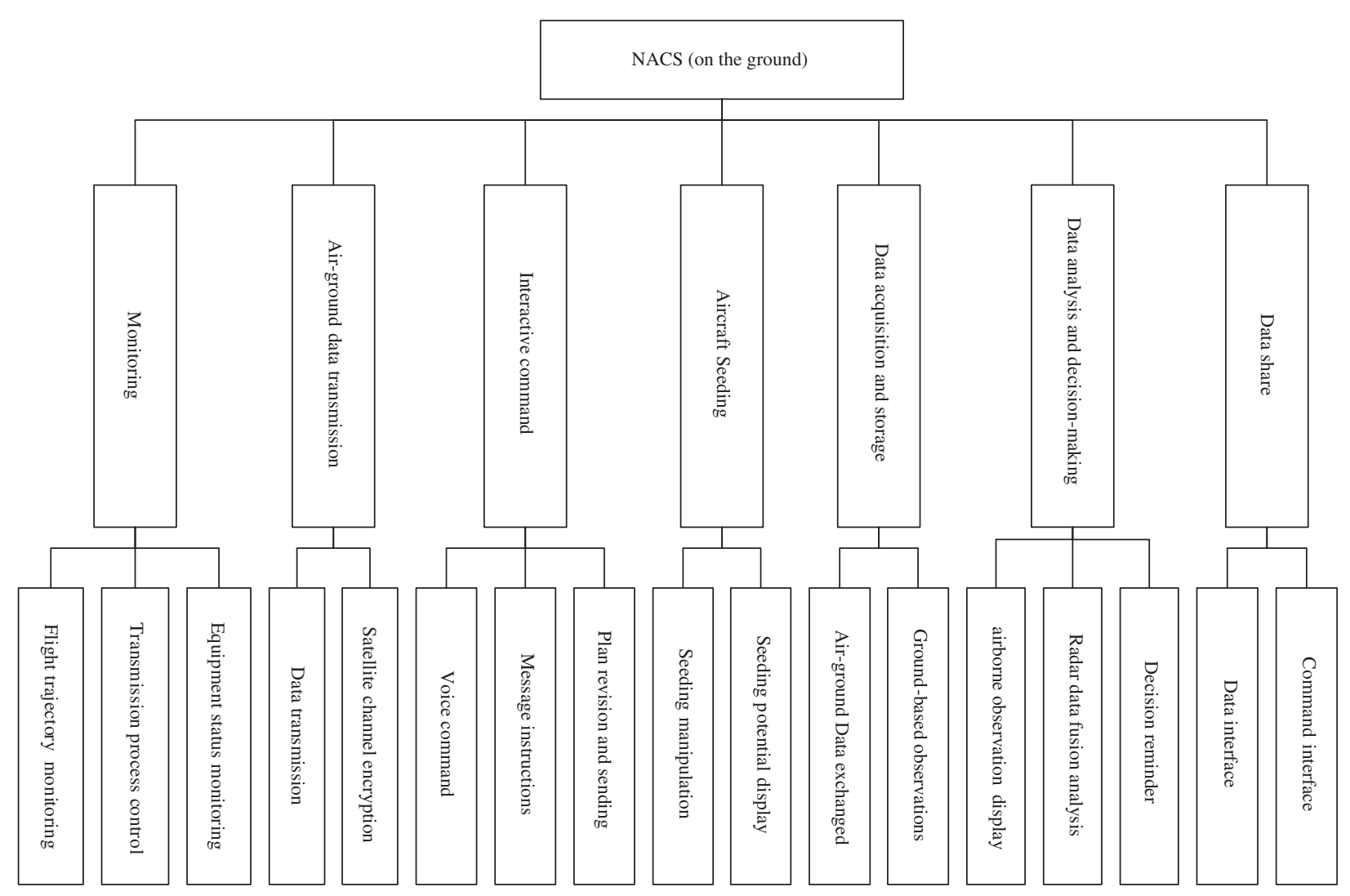

Figure 4: Functional structure of NACS

NACS was first deployed in the weather modification departments of various provinces to form multiple ground command centers and in the national weather modification center (WMC) as part of the National Command Center in 2016. NACS currently supports three national-level high-performance aircraft and more than 40 provincial-level aircraft to participate in various major service assurance processes, such as drought relief, rain enhancement, and forest/grassland fire suppression. At present, the number of aircraft being monitored, commanded and data shared within NACS has reached approximately $90 \%$ of the total number of Chinese weather-modification aircraft (see Tab. 4).

\subsection{Experiment and Case Analysis}

Fig. 5 shows the user interface of the air-ground communication command system during the weathermodification experiment with two airplanes in Ningxia Province, China, in September 2018, i.e., the main interface on the ground center and the display interface for airborne observation data. NACS has a 
graphical drawing interface on the ground, which is similar to DMT's PADS software on the airplane, to synchronously display the spectrum distribution of particles detected in the cloud by the aircraft.

Table 4: Coverage of China's weather-modification aircraft

\begin{tabular}{lll}
\hline Region & Number of existing aircraft & Command scope of NACS \\
\hline North China & 17 & 16 \\
Northeast China & 6 & 5 \\
Northwest China & 11 & 10 \\
Central China & 6 & 4 \\
Southeast China & 4 & 4 \\
Southwest China & 7 & 7 \\
\hline
\end{tabular}

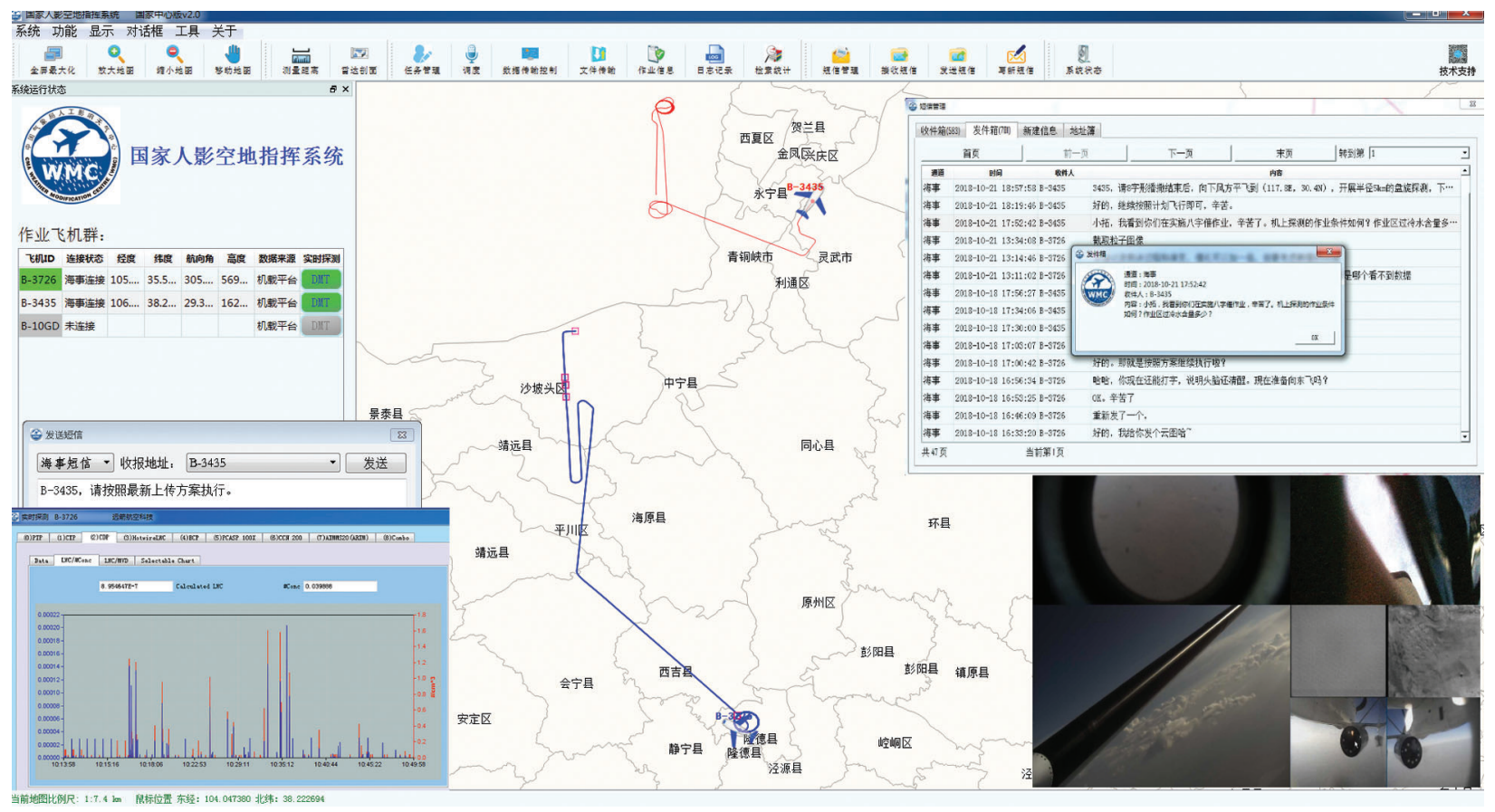

Figure 5: Command for weather-modification aircraft in NACS

In a typical weather-modification aircraft seeding operation in 2019, NACS coordinated 5 ground command centers using Inmarsat satellite communications to command 5 high-performance aircraft and Beidou satellite communication to monitor and command more than 20 general-operation aircraft. NACS maintains continuous air-ground communication and smooth display of observation data, which improves the efficiency of air-ground cooperation and provides powerful application support for successful cloud seeding.

In November 2020, for an experiment of precipitation enhancement, when aircraft No. B-102P entered the designated seeding area, the cloud microphysical parameters of airborne observations received by NACS in the ground command center were obviously much better than the seeding parameters previously predicted 
by the numerical model. According to the decision-making reminder, the ground command center immediately displayed and analyzed the air-based and ground-based fusion data and changed the original seeding plan in terms of the seeding area expanded and seeding dose increased. The new seeding plan was quickly uploaded to the aircraft operators through the air ground communication system to ensure that the seeding efficiency was related to changes in cloud conditions.

\section{Summary and Discussion}

A novel framework named FACT was designed and implemented for air-to-ground communication to improve the cloud seeding effectiveness. To improve the efficiency of information exchanged between the air and ground, FACT provides a set of solutions from three perspectives: onboard, ground and air-toground. On-board ensures stable acquisition of airborne observations, ground is responsible for data fusion analysis, decision-making and sharing, while air-to-ground solves the real-time transmission stability of satellite channels.

FACT uses Beidou/maritime dual satellite links to interactively command weather modification aircraft. It also proposes an algorithm based on the quality of the satellite transmission channel to dynamically adjust the amount of downlink airborne observations to avoid congestion. Moreover, it solves the problem of continuous downward transmission of airborne observations from air to the ground center. When both airbased and ground-based observations are acquired in the ground center, a decision tree is constructed by training key features from those data, which is capable of automatically judging the seeding potential and assisting experts on the ground in deciding whether to change the flight route or cloud seeding parameters.

Additionally, an application named NACS, which is based on FACT, is designed and implemented for the command system of weather-modification aircraft. Experiments over the past few years have established NACS as the key system in the WMC and in many provinces of China for aircraft communication when conducting weather modification seeding plans.

However, some parts of FACT require further improvement. When there is no operation condition information, the data generated by the detector can be filtered and preprocessed before being transmitted to reduce the data flow and cost. The ground units can further increase the data fusion products and upload them to the aircraft in real time to further enhance the decision-making ability of the aircraft and enrich the data display.

Acknowledgement: The authors acknowledge the editor and referees for helpful comments. We also thank Yang Gao and Hongyu Li for valuable discussions.

Funding Statement: This research was jointly funded by the National Key R\&D Program of China (Grant Number 2018YFC1505702) and the project of scientific research on weather modification in Northwest China, research for experimental design and application integration (RYSY201909).

Conflicts of Interest: The authors declare that they have no conflicts of interest to report regarding the present study.

\section{References}

[1] X. Guo, D. Fu, X. Li, Z. Hu, H. Lei et al., "Advances in cloud physics and weather modification in China," Advances in Atmospheric Sciences, vol. 32, no. 2, pp. 230-249, 2015.

[2] D. Rosenfeld, D. Axisa, W. L. Woodley and R. Lahav, "A quest for effective hygroscopic cloud seeding," Journal of Applied Meteorology and Climatology, vol. 49, no. 7, pp. 1548-1562, 2010.

[3] B. A. Silverman and W. Sukarnjanaset, "Results of the Thailand warm-cloud hygroscopic particle seeding experiment," Journal of Applied Meteorology and Climatology, vol. 39, no. 7, pp. 1160-1175, 2000. 
[4] L. Xin and Z. Yao, "Studies on the microphysical characteristics of an aircraft seeding in convective line with trailing stratiform cloud," Meteorological Monthly, vol. 2, no. 10, pp. 68-76, 2011.

[5] H. Jin, M. Huang, X. Yu, J. Liu, H. He et al., "Preliminary analysis of in-situ measurements in warm cloud after seeding with hygroscopic flares," Climatic and Environmental Research, vol. 17, no. 6, pp. 704-710, 2012.

[6] D. Zhou, F. Gong, J. Wang, Z. Li and J. Gao, "The studies of the microphysical characteristics of aircraft cloud seeding," Scientia Meteorologica Sinica, vol. 24, pp. 405-412, 2004.

[7] C. Guo, C. Gong, J. Guo, Z. Wei and S. Z. Khan, "Software-defined space-air-ground integrated network architecture with the multi-layer satellite backbone network," Computers, Materials \& Continua, vol. 64, no. 1, pp. 527-540, 2020.

[8] D. Corral-Plaza, J. Boubeta-Puig, G. Ortiz and A. Garcia-de-Prado, "An internet of things platform for air station remote sensing and smart monitoring," Computer Systems Science and Engineering, vol. 35, no. 1, pp. 5-12, 2020.

[9] S. Kim and D. Kim, "Adaptive data transmission method according to wireless state in long range wide area networks," Computers, Materials \& Continua, vol. 64, no. 1, pp. 1-15, 2020.

[10] Q. Wang, C. Yang, Y. Wang and S. Wu, "Application of low cost integrated navigation system in precision agriculture," Intelligent Automation \& Soft Computing, vol. 26, no. 4, pp. 1433-1442, 2020.

[11] V. J. Schaefer, "The production of ice crystals in a cloud of supercooled water droplets," Science, vol. 104, no. 2707, pp. 457-459, 1946.

[12] B. Vonnegut, "The nucleation of ice formation by silver iodide," Journal of Applied Physics, vol. 18, no. 7, pp. 593-595, 1947.

[13] S. A. Tessendorf, J. R. French, K. Friedrich, B. Geerts and R. Bruintjes, "A transformational approach to winter orographic weather modification research: The SNOWIE project," Bulletin of the American Meteorological Society, vol. 100, no. 1, pp. 71-92, 2019.

[14] J. R. French, K. Friedrich, S. A. Tessendorf, B. Geerts and D. R. Blestrud, "Precipitation formation from orographic cloud seeding," Proceedings of the National Academy of Sciences, vol. 115, no. 6, pp. 1168-1173, 2018.

[15] B. Chen and X. Hui, "Silver iodide seeding impact on the microphysics and dynamics of convective clouds in the high plains," Atmospheric Research, vol. 96, no. 2-3, pp. 186-207, 2010.

[16] Y. Qu, A. Khain, V. Phillips, E. Ilotoviz, J. Shpund et al., "The role of ice splintering on microphysics of deep convective clouds forming under different aerosol conditions: Simulations using the model with spectral bin microphysics," Journal of Geophysical Research: Atmospheres, vol. 125, no. 3, pp. 7, 2020.

[17] B. Chen and Y. Yin, "Can we modify stratospheric water vapor by deliberate cloud seeding?," Journal of Geophysical Research: Atmospheres, vol. 119, no. 3, pp. 1406-1418, 2014.

[18] Q. Liu, D. Zhang and W. Liu, "Application of Beidou ground to air communication command system in aircraft Precipitation enhancement," Journal of Anhui Agricultural Sciences, vol. 42, no. 28, pp. 9856-9857, 2014.

[19] C. Du, J. Ding, H. Li, X. Ma and M. Yang, "Construction and application of the air-earth information transmission system of airplane precipitation enhancement operation in Henan," Meteorological and Environmental Sciences, vol. 32, no. 2, pp. 85-88, 2014.

[20] J. Leinonen, A. Guillaume and T. Yuan, "Reconstruction of cloud vertical structure with a generative adversarial network," Geophysical Research Letters, vol. 46, no. 12, pp. 7035-7044, 2019.

[21] J. Jeppesen, R. Jacobsen, F. Inceoglu and T. Toftegaard, "A cloud detection algorithm for satellite imagery based on deep learning," Remote Sensing of Environment, vol. 229, no. 8, pp. 247-259, 2019.

[22] S. Rasp and S. Lerch, "Neural networks for post-processing ensemble weather forecasts," Monthly Weather Review, vol. 146, no. 11, pp. 3885-3900, 2018.

[23] C. Wang, P. Liu, K. Jia and X. Jia, "Identification of weather phenomena based on lightweight convolutional neural networks," Computers, Materials \& Continua, vol. 64, no. 3, pp. 2043-2055, 2020.

[24] L. Zhu, Z. Wu, L. Wang and Y. Wang, "The identification of the wind parameters based on the interactive multimodels," Computers, Materials \& Continua, vol. 65, no. 1, pp. 405-418, 2020. 
[25] M. Wei, N. Zhang, Y. Tong and Y. Song, "Research on the advanced prediction model of the tunnel geological radar based on cluster computing," Intelligent Automation \& Soft Computing, vol. 26, no. 3, pp. 597-607, 2020.

[26] S. Wang, X. Yu, L. Liu, J. Huang, T. H. Wong et al., "An approach for radar quantitative precipitation estimation based on spatiotemporal network," Computers, Materials \& Continua, vol. 65, no. 1, pp. 459-479, 2020.

[27] S. Han, J. Seo, D. Kim, S. Kim and H. Lee, "Development of cloud based air pollution information system using visualization," Computers, Materials \& Continua, vol. 59, no. 3, pp. 697-711, 2019.

[28] L. Aguilar, S. W. Nava-Díaz and G. Chavira, "Implementation of decision trees as an alternative for the support in the decision-making within an intelligent system in order to automatize the regulation of the VOCS in nonindustrial inside environments," Computer Systems Science and Engineering, vol. 34, no. 5, pp. 297-303, 2019. 